\title{
Are Sportsmen Willing to Practice Sports during their Holidays? The Case of Sports Faculty Students in France
}

Authors' contribution:

A) conception and design of the study

B) acquisition of data

C) analysis and interpretation of data

D) manuscript preparation

E) obtaining funding

\author{
Yann Abdourazakou ${ }^{1 \text { A-E }}$, Guillaume Penel ${ }^{2}$ A-D , \\ Philippe Masson ${ }^{2 C, D}$ \\ ${ }^{I}$ Canisius College, USA \\ ${ }^{2}$ University North of France, France
}

ABSTRACT

The study was conducted in northern France at the sport management department at the University of Lille. It attempts to highlight the type of summer vacation of its students. Previous studies have shown the modalities of mobility (Urry, 2000; Seewer, 2004). Although models exist to explain destination choice, many of these have limitations, including the assumption of a rational consumer and a focus on the functional attributes of travel and tourism (Lewis, Kerr, \& Pomering, 2010). However, few studies handle the behavior of consumption of students during their holidays, especially the sports students. In making their travel decisions, consumers assess the attractiveness of a destination (Sirakaya et al., 2001). Positive associations with a destination increase the likelihood of selection (Woodside \& Lyson-ski, 1989). The main hypothesis concerned the type of sports that students were engaged while on vacation. That is, we postulated that students also practiced sport during their vacation time. The second hypothesis concerned the mobility that these students should be accustomed to in order to travel in competitions abroad or at least away from home. The study was conducted in a quantitative manner, with questionnaires $(\mathrm{N}=451)$. The main results are based on 451 Physical Education (PE) students from the area of Lille, France, who participated in this study. In this population, $55.2 \%$ were single, $44.8 \%$ were married or in a relationship $(10.2 \%$ had children). Initial results show that the average household income per month is about EUR 2,500; over 74\% of them go on holiday for two weeks, on average. These students are coming from wealthy families. When they say that they are "going on vacation", a majority of them $(68.7 \%)$ indicate that the main reason is to relax. Contrary to the announced hypothesis, few PE students (4.9\%) wish to practice physical activities during the holiday. Independently, we noticed that a majority of student $(79.5 \%)$ preferred a single destination when the purpose was to make cultural trips $(51.5 \%)$. However, the question of the budget remains an issue and they favor $(78 \%)$ being hosted in the cheapest accommodations. For instance, the accommodations concerned are mostly camping or holiday villages. These findings can be interesting to satisfy this kind of demand and help providers build better strategies.

KEYWORDS mobility, youth, holidays, tourism, sport

\section{Introduction}

The student travel market is a very important segment in the travel industry. It constitutes $20 \%$ of all international travelers (Frost \& Shanka, 1999). Sports activities and leisure activities are a relatively privileged segment in the current tourism sector. Nevertheless, we noticed a lack of evident connection 
between everyday life behavior and the way people act during their holidays. Vacations are often perceived as a total break. However, better understanding in consumption practices during the holidays is needed to understand the place granted sports practices in general and according to various tourists' profiles. Nowadays, tourism offer is plethoric. Acknowledging that variety, we focused on the young individuals (1825 years old) for whom the development of tourism seems to follow two major trends: in the short term, the holiday departure participates in the construction and in the acquisition of the autonomy of young. It also contributes in the long run to the renewal and to the development of tourism consumers. As we know, the current young vacationers will be the tourists of tomorrow. For many authors, sports tourism is an important trend in today's market (Pigeassou, 2004; Bouahouala, 2004; Chazaud, 2004; Sobry, 2005; Bouchet, 2009). In this perspective, sports and leisure activities shape holidays.

Beyond the preoccupation with the hygienist or stylistics, we have to admit that we are observing the emergence of very specific offers today. In general, consumers perceive overseas travel as more exotic and prestigious than domestic tourism (Dolnicar, 2005; Tourism Research Australia, 2007). Younger consumers of travel might hold an attitude that one can visit these destinations later in one's life (Woodside \& Lysonski, 1989). Nevertheless, the time of holidays is a peculiar moment. Lived in a very different way according to aspiration and to different profiles, we are brought to wonder about an automatic transfer of the regular sports behavior during everyday life towards individuals' holidays. Indeed, the desire for disorientation and escape can be transformed in a will to have a peculiar practice. On the contrary, people can wish to invest time in sports activities in their holidays for the most sedentary. Based on this interrogation, we questioned a population ( $\mathrm{N}=451)$ of Physical Education students (registered in the Faculty of Science of Sport) to identify their consumption behavior during the holidays in particular trying to identify the place held by sports. The goal of this study is to improve the knowledge of tourist behavior in a context of competitive offers and to also debate possible managerial and strategic issues.

Our approach aims at investigating the behaviors of the young student vacationers of the Region NordPas-de-Calais. Numerous exchange programs of (ERASMUS; CREPUQ) testify to the students' craze for mobility. According to Mitchell (1991), there are three major constituents of analysis in the tourist field, which are the place, the weather, and the activities.

The north of France, located at the European crossroads, offers a privileged ground of analysis allowing for the seizing of a possible apprenticeship (i.e. a predisposition) of mobility. Finally, by focusing on sports students, our study attempts to see if sports practices have an impact by creating a greater mobility. Indeed, the sports competitor is committed, by nature, in meetings that are favoring mobility. These three characteristics (students; Nordic; sportsmen) favor a peculiar mobility. Students in sport sciences want all to practice physical and sports activities during the time of the holidays. To do it, it is necessary to seize the motivations and the behaviors of this demand and to better understand the content of the "motilities' black box" of various types of vacationers according to the segmentation.

\section{The mobility at the young people: state of research}

The 2008 energy crisis profoundly upset tourists' travels worldwide. The recent period with the rise of oil prices and the more recent context of leadership crisis of purchase offer interesting teachings on a certain number of trends. The motivations of the vacationers are at once simple (rest, disorientation, userfriendliness, conviviality), and complex in terms of availability and purchasing power (division of the holidays). Dureau and Hily (2009) suggest: "speaking about mobility, it is at first to question the travels in the space, but also the opportunities which they enjoy or on the contrary the brakes which hinder them. To question the mobility, it also is to consider the social processing which it produces and the new forms of socialization which she can establish".

Indeed, the type of mobility and the specific behavior of consumption influence the experience feedback and the criteria of choice. Recent studies showed that the young French students are dedicated to the mobility within the framework of their studies (Campus France, 2008; Minister of higher education and 
research; Minister of Foreign and European Affairs; Council of Europe). Inquiries of the CEREQ specify that $32 \%$ of graduates of higher education changed regions between the sixth grade (students aged 11 years in France) and their release from the educational system. Can we transfer for all this type of mobility chosen or undergone within the framework of the studies and sport to that of the behavior observed during the holidays? The mobility recovers several dimensions according to the time chosen (the holidays) and depending on the space in which it occurs.

The mobility factors are present, in fact, before the matter of field studies and the university trajectory. Indeed, numerous criteria, such as gender, the social and occupation of parents, personal educational background, and family culture, can influence migratory behavior during holidays. Young men are more mobile than young women (Mincer, 1978; Length 1988). However, other studies (Masson, 2002; Pailhé \& Solaz, 2001) clearly indicate that at the beginning of a career, young women are more mobile. One of the major reasons is a will to leave parental control faster. The financial means of the parents, without being a crippling brake in mobility, are going to widen or not the field of possibilities. Financial support then becomes a more important central element.

Nevertheless, the status of being single or being in a couple without children can also allow, to a certain extent, less early projects. However, this last element remains to be discussed; in particular, when considering vacationer profiles. The last aspect is the family culture. Indeed, the type of cross holidays, being a child, the location (rural, urban) have a clear influence on the desire or not to live in a state of mobility; that is, mobility leads to mobility (Pailhé \& Solaz, 2001).

\section{The tourist behavior of young people}

Generation Y, born between 1977 and 1994 (Kotler et al., 2006), has been identified as one of the hardest target for tourism marketers to attract (Dorman, 2009; Jones, 2009). The main teachings concerning the own modes and the references in term of tourist consumption of the young people are the following ones:

- The young client is a channel-hopper, difficult to develop loyalty with;

- The Internet is their main information source, because $91 \%$ of them declare to use Web to plan the journeys;

- Tourism of young people is evenly distributed over the year with nearly half of the stays occurring outside the summer period, thanks to school and student journeys.

The rate of holiday departure of the young adults (18 - 25 years) has recently experienced a sensitive decline, largely connected to the economic issues (studies costs on the long run, job insecurity, casual jobs (small jobs), training courses, unemployment). Besides these factors, youngsters represent the grown-up clientele of tomorrow for the people working in the tourist industry. A loss of their holiday culture can have disastrous medium-term consequences. To take only an example, raised by the elected representatives of the mountain, a generation that would leave winter sports would remove any motivation from the following generation. The literature also indicated that leisure activities are an important part of people's lifestyles. In fact, activities determine people's lifestyles (Glyptis, 1981). Glyptis (1981) examined the leisure activity patterns of countryside visitors in the Hull area (United Kingdom) and reported that people vary in their leisure activity patterns. Graham and Wall (1978) analyzed the activities of American visitors to Canada and grouped the visitors in four relatively distinct market segments: sightseeing, commercial activities, wateroriented activities, and outdoor living. Each group was found to exhibit different interests and preferences for activities.

\section{Problem, hypotheses, and method}

According to a review of the literature, we noticed important issues connected to the mobility of the young sports students during their holidays. Analysis of their dominant behavior has allowed us to identify the factors that influence their holidays in order to better target this type of consumers. Our research allows 
us to test two hypotheses. The first one would be that sports students tend to be more mobile in particular because of sports practice and competition. It helps them get used to mobility and to a type of travel frequency. The second would be that sport is not a relevant variable in the choice and options available in holiday practices. Pull factors explain the destination(s) chosen and are influenced by the perceived image of a destination including atmosphere, activities, climatic conditions, scenery, culture, lifestyle, and the social environment (Yoon \& Uysal, 2005). The time of holiday would be collected more as a moment of break with the everyday life and consequently underestimated in the choice of holidays. In making their travel decisions, consumers assess the attractiveness of a destination (Sirakaya et al., 2001). Positive associations with a destination increase the likelihood of selection (Woodside \& Lysonski, 1989).

How do the young people choose their holidays? How do they prepare for them? What choice of activities, mode of travel, or accommodation is chosen? The choice of this segment is connected to simple observations: the lack of studies on the subject, and the progress of this segment in tourism (8\% in the total value of the business, according to the World Tourism Organization). This shows the strong incentive of young people to travel and a more internationalized generation as well. The fact is also that this segment represents tourist consumers with strong purchasing power. Within the framework of our study, we reached $451 \mathrm{PE}$ students with our questionnaire. The results were analyzed under the software Sphinx Lexica ${ }^{2}$. A statistical analysis then allowed us to identify the main results and the correlations between different variables.

\section{Results and discussion}

Our sample is distributed according to the variables provided in table 1.

Table 1. Characteristics of the group

\begin{tabular}{|c|c|c|}
\hline \multicolumn{2}{|c|}{ Age group (years) } & $18-25$ \\
\hline \multicolumn{2}{|c|}{ Referees $(\mathrm{N})$} & 451 \\
\hline \multicolumn{2}{|l|}{ Level } & Licence and Master Sport sciences \\
\hline \multirow{3}{*}{ Status $(\%)$} & Single & 53 \\
\hline & In couple & 37 \\
\hline & In couple with kids & 10 \\
\hline
\end{tabular}

Source: own study.

At first, we noticed that $74 \%$ of our sample declares to have gone on holiday in 2010. It shows the strong mobility of the students (the average duration of stay is two weeks). The sports students seem to prefer making journeys with other people (collective) or at least in couple. They are not on the mode of the explorer / adventurer. We notice that $24.6 \%$ of the students went abroad to mainly European or North African destinations, which shows a similarity with national results. The sample is thus not more mobile than other groups of the same age category. Nevertheless, we noticed that this segment appears little sensitive to the destination as long as its expectations in terms of experiences and sensations are quenched. On this subject, Pauchant (2003) tells us that: "it is in this segment that we find least interest for the destination. It seems that the activity dominates on quite other consideration for the choice of a sequence of holidays, whether it is in the country or international". The major factor for young people is the climate. It dominates the activities and the destination. Indeed, we noticed that the dominant variables are climatic conditions (53.2\% answered very important) and cheap hosting (24.3\% answered very important).

To identify the peculiarities of our sample, we questioned them about the main motives for holiday departure. We noticed that the purpose "to relax and get fresh ideas" is mainly placed (69\% of the sample). The second motive is the fact of leaving "to practice sports activities" ( $4.9 \%$ of the sample). Finally, a minor incentive concerns "cultural entertainment" (1.6\%). We noticed that the variable "sports and cultural practices" is not important. It shows that sports opportunities of the chosen location counts little or not at all in the holiday choice. These figures come to confirm the more global results of the study carried out by minister of the health, the youth and the sports in 2007, and in which the young people aged from 20 to 24 years cited the social relationships and the willingness to relax as important during their holidays. However, 
culture and sports practice do not constitute the main motivation of their holidays. Consequently, we noticed that the profile "students in faculty of sports" has no significant effect at all in this regard. The mobility aspect is also to be handed in perspective in the framework of our approach. Indeed, we noticed that $79.5 \%$ of the people chose a unique destination. Thus, mobility turned out to be limited.

Finally, we also wished to know the modalities of reservation and/or information about the destinations. To do so, we questioned them about the use of Internet. Without surprise, we noticed that the use of Internet is strategic for this type of consumers (64\% use it in order to prepare their holidays). It allows them to look for relevant information, but especially to compare offers, to obtain more advantageous price rates $(33.7 \%)$, and to make reservations and buy $(37.9 \%)$.

\section{Conclusions and perspectives}

This explanatory study needs to be pushed forward. We need to overcome the limits resulting of the geographic location of our respondents. Nevertheless, there does not seem to be significant differences in the social recruitment in this type of university compared to others. The various studies done on the tourists' trends often bring forward expectations of convenient order (price, quality, comfort, or choice of formula), which can allow establishing a typology. The typology of the tourist behavior would then aim at "summarizing" multiple variables linked to tourists' behavior. This analysis allowed us to identify different groups (according to the most discriminating behavior), to quantify the importance of these groups, to analyze the profile of each of them, to understand their needs, to target growth areas for the future. The behavior is shaped by the types of stays (duration and accommodation) and activities (types and number). Actual destination choice is, however, affected by both the intention to visit and situational variables such as time, financial resources, and the opportunity to travel (Oppermann, 1999; Woodside \& Lysonski, 1989). Other variables such as income, household size, age, employment, and city of origin may also influence destination choice (Barros et al., 2008; Nicolau \& Más, 2005). However, we verify those previous findings.

Within this work we admitted a certain consistency in behavior. Indeed, sports students are mobile at an identical importance of other students or the individuals of the same age group. Sport does not seem to develop a peculiar mobility. The stay is generally for a unique destination for an average duration of two weeks. The main dominant factor is the climatic conditions. It can turn out to be very important to notice that the study was made in the north of France, which is known for its bad weather. Cheap accommodation is also a variable that matters. At this stage we cannot supply a real typology. We identified a considerable amount of identical behavior, which could be explained by the relative social and cultural homogeneity of these students.

The main results of this study showed that sports followers in everyday life do not automatically tend to duplicate their lifestyle during their holidays. It raises concerns about offering proposals in tourism and especially strategies used by business firms or tourism organizations for this target. Indeed, except for core sports followers, it seems that the offer must be more differentiated according to the kind of public. Youngsters are a different kind of target in need of a break from their everyday life practices. This gives opportunities for providers who wish to satisfy this kind of consumers in the future.

The study of the consumption behavior then turns out to be unique tool for practitioners in managing sports, leisure activities, and tourism in general. If marketers are to reverse the decline in domestic tourism, there needs to be a better understanding of the nature of travellers. As competition intensifies among tourism destinations, deeper insight into the destination choice process may provide a destination with a competitive advantage (Thrane, 2008). The study demonstrated that an analysis of tourist behavior must measure the multifaceted structure of young tourists' behavior. We suggest that future research on this topic should be further aimed at other international groups of students in order to detect possible model equivalences across several data sets and to enable the generalization of our findings. 


\section{REFERENCES}

Barros, C.P., Butler, R., Correia, A. (2008). Heterogeneity in Destination Choice: Tourism in Africa. Journal of Travel Research, 47(2), 235-46.

Bouahouala, M. (2004). Petites entreprises du tourisme sportif / Sport Tourism Enterprise/. Grenoble: Presses universitaires de Grenoble.

Bouchet, P., Lebrun, A.M. (2009). Management du tourisme sportif. De la consommation à la commercialization /Sport Tourism Management from consumption to commercialization/. Rennes: Presses universitaires de Rennes.

Chazaud, P. (2004). Management du tourisme et des loisirs sportifs de pleine nature /Tourism management and the great outdoor sport/. Voiron: Presses universitaires du sport.

Dolnicar, S. (2005). Understanding Barriers to Leisure Travel -Tourist Fears as Marketing Basis. Journal of Vacation Marketing, 11(3), 197-208.

Dureau, F., Hily, M.A. (2009). Les mondes de la mobilité /The mobility world/. Rennes: Presses universitaires de Rennes.

Frost, F., Shankra, T. (1999). Asian Australian Student Travel Preferences - An empirical study. Proceedings of Asia Pacific Tourism Association Fifth Annual Conference 23-25 August 1999 (pp. 142-151). Hong Kong: The Hong Kong Polytechnic University.

Marzloff, B. (2005). Mobilités. Trajectoires fluids /Mobility. Fluids trajectory/. Paris: éd. de L'Aube.

Masson, P. (2002). European Dimension And Teacher Training. International Journal of Educational Policy Research and Practice, 3(1), 41-57. San Francisco : Caddo Gap Press.

Mitchell, L. (1991). A conceptual matrix for the study of tourism. Cahiers du Tourisme, Serie C, 146. Centre des Hautes Etudes Touristiques.

Nicolau, J., Más F.J. (2005). Stochastic Modelling: A Three-Stage Tourist Choice Process. Annals of Tourism Research, 32(1), 49-69.

Oppermann, M. (1999). Predicting Destination Choice - A Discussion of Destination Loyalty. Journal of Vacation Marketing, 5(1), 51-65.

Pauchant, E. (2003). La fin du jeunisme/The end of youth age/ . In Tourisme des jeunes (16-25 ans) /Tourism of youngters/. Cahiers Espaces, 77, 16-20.

Penel, G., Abdourazakou, Y., Masson, P. (2011). Le comportement touristique des jeunes sportifs /Tourism behavior of young sportsmen/. Revue Juristourisme, Editions Dalloz.

Pigeassou, C. (2004). L'invention du tourisme sportif /The creation of sport tourism/. Grenoble: Presses universitaires de Grenoble.

Sirakaya, E., Sonmez, S., Choi, H.S. (2001). Do Destination Images Really Matter? Predicting Destination Choices of Student Travellers. Journal of Vacation Marketing, 7(2), 125-42.

Sobry, C. (2005). Le tourisme sportif /Sport Tourism/. Presses universitaires du Septentrion.

Thrane, C. (2008). Earnings differentiation in the tourism industry: Gender, human capital and sociodemographic effects. Tourism Management, 29(3), 514-524.

Woodside, A., Lysonski, S. (1989). A General Model of Traveller Destination Choice. Journal of Travel Research, 27(8), 8-14.

Yoon, Y., Uysal, M. (2005). An Examination of the Effects of Motivation and Satisfaction on Destination Loyalty: A Structural Model. Tourism Management, 26(1), 45-56.

\section{AUTHOR'S ADDRESS: $\quad$ Yann Abdourazakou}

Department of Sport Administration

Institute of Research in Sport (IRIS)

Canisius College

2001 Main Street, Buffalo NY 14208

Horan-O'Donnell, 014B

USA

Email: abdouray@canisius.edu 